Instructions for authors, subscriptions and further details:

http://qre.hipatiapress.com

\title{
Critical Reflection on Own Beliefs for Cultural Competence in Medical Education: an Analysis of Tutors' Reflective Narratives
}

Costas S. Constantinou ${ }^{1}$, Panayiota Andreou ${ }^{1}$, Alexia Papageorgiou ${ }^{1}$ \& Peter McCrorie ${ }^{1}$

1) Medical School, University of Nicosia, Cyprus.

Date of publication: October $28^{\text {th }}, 2020$

Edition period: October 2020 - February 2021

To cite this article: Constantinou, C. S., Andreou, P., Papageorgiou, A., \& McCrorie, P. (2020). Critical Reflection on Own Beliefs for Cultural Competence in Medical Education: an Analysis of Tutors' Reflective Narratives. Qualitative Research in Education, 9(3), 273-299. doi:10.17583/qre.2020.5063

To link this article: http://dx.doi.org/10.17583/qre.2020.5063

\section{PLEASE SCROLL DOWN FOR ARTICLE}

The terms and conditions of use are related to the Open Journal System and to Creative Commons Attribution License (CC-BY). 


\section{Critical Reflection on Own Beliefs for Cultural Competence in Medical Education: an Analysis of Tutors' Reflective Narratives}

Costas S Constantinou

University of Nicosia

Alexia Papageorgiou

University of Nicosia
Panayiota Andreou

University of Nicosia

Peter McCrorie

University of Nicosia

(Received: 15 January 2020; Accepted: 24 September 2020; Published: 28 October 2020)

\section{Abstract}

Critical reflection on own beliefs, within the context of cultural competence, has been acknowledged as an important skill doctors and medical students should have in order to enhance the quality of health care regardless of patients' social and cultural background. Yet the guidelines for teaching students critical reflection on their own cultural beliefs are lacking. Based on the method of investigating short reflective narratives and Gibbs' reflective cycle for development, this paper explores the experience of clinical communication tutors' in examining cultural competence in OSCEs, how they felt, analyzed and concluded, and examines their account on how to construct a training model for dealing with such challenge in medical education.

Keywords: Criticial reflection on own beliefs, cultural competence, medical education, reflective narratives 


\section{Reflexión Crítica Sobre las Propias Creencias en Relación a la}

\section{Competencia Cultural en la Educación Médica: un Análisis de las Narraciones Reflexivas de los Tutores}

Costas S Constantinou

University of Nicosia

Alexia Papageorgiou University of Nicosia
Panayiota Andreou

University of Nicosia

Peter McCrorie

University of Nicosia

(Recibido: 15 de enero de 2020; Aceptado: 24 de septiembre de 2020; Publicado: 28 de octubre de 2020)

\section{Resumen}

Se ha reconocido que la reflexión crítica sobre las propias creencias, en el contexto de la competencia cultural, es una habilidad importante que deben tener los médicos y los estudiantes de medicina para mejorar la calidad de la atención de la salud, independientemente de los antecedentes sociales y culturales de los pacientes. Sin embargo, faltan las directrices para enseñar a los estudiantes la reflexión crítica sobre sus propias creencias culturales. Basándose en el método de investigación de las narraciones reflexivas cortas y el ciclo de reflexión de Gibbs para el desarrollo, este documento explora la experiencia de los tutores de comunicación clínica en el examen de la competencia cultural en las OSCEs, cómo se sintieron, analizaron y concluyeron, y examina su relato sobre cómo construir un modelo de formación para hacer frente a ese desafío en la educación médica.

Palabras clave: reflexión crítica sobre las propias creencias, competencia cultural, educación médica, relatos reflexivos 
e have just finished the briefing with students about the OSCE exams. It was such an overwhelming and tiring session, students killed [heavily criticized] the station on cultural competence as they thought it was unrealistic and that it put them in a disadvantage. They exaggerated everything, they just couldn't leave their own beliefs outside this." (clinical communication tutor, University of Nicosia)

These were the words expressed by a clinical communication skills tutor, with disappointment expressed on her face, at the University of Nicosia. A cultural competence OSCE station was used to examine students' skills. The station was about a Muslim patient with diabetes who wanted to fast during Ramadan, could not follow the recommended diet and wanted support from her doctor. Students were expected to demonstrate their cultural competence by listening to the patient's perspective and concerns, not being judgmental, acknowledging and validating the patient's viewpoint and working with the patient to find a suitable management plan. After the exam, there was a debrief session in order for both examiners and students to reflect and discuss. On the one hand, students, especially the Muslim ones, were upset and expressed serious concerns about the preparation of the station. On the other hand, the tutors who had worked on the station and examined the students were confused as they thought they had prepared a good and wellbalanced station. Tutors initially concluded that it was students' fault who could not leave aside their own beliefs about Islam and fasting.

This triggered us to explore more the tutors' perspective, their experience and any potential action plans. We approached the tutors' expressions as reflective narratives in order to better understand how the tutors experienced this particular event. This is analyzed in more detail under Method and Findings. Before we explain the method we used and the findings from the tutors' narratives, let us first explore the importance of cultural competence in medical education and the skill of critical reflection on own beliefs.

There is a wealth of literature regarding definitions, skills and models of training in cultural competence in health care (Alizadeh \& Chavan, 2016). In general, health care professionals are culturally competent when they have knowledge in social and cultural determinants of health, they understand how these factors relate to each other, and they apply interventions to provide the best quality care regardless of patients' social and cultural background 
(Betancourt et al., 2003). Though there are many guidelines on how to train doctors in cultural competence, the way to achieve this in medical education is lacking (Sorensen et al., 2019; Constantinou et al., 2018; Hudelson et al., 2016) and any models which exclusively focus on teaching students how to critically approach and handle their own beliefs are lacking. It is this gap that this paper aims to fill in by analysis tutors' reflective narratives reflecting and conceptualising a training model in critical reflection on own beliefs for medical students.

The need for cultural competence in health care has been acknowledged and documented in the literature for a number of reasons. First, cultural competence can be linked with better patient satisfaction and develop a sense of social integration (Waxler-Morrison, 2007). Second, contemporary societies are increasingly becoming multi-cultural and cultural competence could better explore and work on ethnic minority groups' health needs; contributing to a reduction in health disparities (Douglas et al., 2014; Betancourt et al, 2003). Third, doctors need to appreciate that health and illness behaviours are complex phenomena affected by different social and cultural factors, reflecting a biopsychosocial approach (Borrell-Carrio et al., 2004). The question is whether cultural competence is effective in terms of improving patient care.

A number of systematic reviews have explored the effectiveness of cultural competence. Price et al.'s (2005) review of studies between 1998 and 2003 and Renzaho et al.'s (2013) review of studies between 2000 and 2011 showed a link between cultural competence and patient satisfaction and adherence to therapy. Though these reviews did not reveal an established association between cultural competence and positive health outcomes, more recent reviews by Horvat et al. (2014) and Alizadeh and Chavan (2016) confirmed the positive impact of cultural competence on healthcare satisfaction and improved adherence to medication.

Reflecting on the importance and effectiveness of cultural competence in health care, many training models for healthcare professionals have been developed. Alizadeh and Chavan (2016) identified 18 models of cultural competence training. These models pinpoint to the importance of developing knowledge, skills and attitudes in order to achieve a good level of competence when working with diversity. In spite of all these models, establishing relevant training in medical curricula has been very challenging. 
More specifically, Hudelson et al. (2016) highlighted that integration of cultural competence in medical education is underdeveloped, while Constantinou et al. (2018) tried to fill in the gap of integrating cultural competence in medical curricula by conceptualising a pyramid model to guide medical programs. A recent study by Sorensen et al. (2019) further supported this identified gap in medical education by showing that the formulation and assessment of learning outcomes in cultural competence in 12 European medical programs has achieved mediocre results.

Specific skills have been outlined in a few models or studies. Among the earlier models of cultural competence are LIVE \& LEARN, the Sunrise, and the Purnell. Carballeira (1997) suggested the "LIVE \& LEARN" model. "LIVE" stands for Like, Inquire, Visit, and Experience, and "LEARN" stands for Listen, Evaluate, Acknowledge, Recommend, and Negotiate. This model focuses on how to approach a patient in a culturally sensitive manner. Culturally competent healthcare professionals should avoid stereotyping and respect patient's beliefs and values. Another model of cultural competence in healthcare is Leininger's "Sunrise Model" (2002). According to this model, healthcare professionals should demonstrate cultural competence by exploring the following: (1) Cultural values and lifeways, (2) Religious, philosophical, and spiritual beliefs, (3) Economic factors, (4) Educational factors, (5) Technological factors, (6) Kinship and social ties, and (7) Political and legal factors.

The Purnell model (Purnell, 2002, p.11) model aimed to be an overarching model which could be used across all disciplines. The model is circular and starts from the outside circle with "global society" and then continues with with community, family and the person. There more specific domains within the generic areas, such as health-care practices, perceptions of health care practitioners, heritage, communication, family roles and organisations, workforce issue, biocultural ecology, high-risk behaviours, nutrition, pregnancy, death rituals, and spirituality. The Purnell model does not focus on any skills but on a list of areas doctors should have knowledge of.

More models or studies support the models above. Based on evidence from the C2ME project doctors should be culturally competent at two levels (Sorensen et al., 2017). First, have knowledge of culture and ethnicity, and how sociocultural factors have an impact on health. Second, acquire skills $n$ working with patients based on their social and cultural background. Kachur 
and Altshuler (2004, p.102-103) presented a more detailed framework. They explained that doctors should have knowledge in "racial/ethnic variability", "multicultural contributions to western medicine", "working with alternative healer", "cultural barriers to investigations", and effect of migration". In addition, cultural competence requires skills such as working effectively with people from other cultures and self-reflection.

Echoing the models above, cultural competence involves knowledge of culture and cultural factors and skills to work effectively with people from various cultural background. Interestingly, two recent studies have further emphasised the significance of critical reflection on own beliefs. First, in their attempt to help nurses become more culturally competent Douglas et al. (2014, p. 2) prepared a draft of guidelines on the basis of 50 documents from nursing, healthcare, governmental and nongovernmental organisations and then immersed the drafted guidelines in a feedback discussion with 78 nurses. The end result included 10 skills, namely: "knowledge of culture, education and training in culturally competent care, critical reflection, cross-cultural communication, culturally competent practice, cultural competence in health care systems, patient advocacy and empowerment, multicultural workforce, cross-cultural leadership, evidence-based practice and research". Highlighting the importance of critical reflection, Douglas et al. (2014, p. $3,4)$ wrote "Nurses shall engage in critical reflection of their own values, beliefs, and cultural heritage in order to have an awareness of how these qualities and issues can influence culturally congruent nursing care".

Second, a more recent study by Hordijk et al. (2018) further supported Douglas et al's findings. Hordijk et al did a Delphi study with 36 experts in cultural competence teaching; the skills that reached $75 \%$ consensus among these experts were: critical reflection on own values and beliefs, communication regardless of background, empathy, awareness of social and cultural determinants of health, intersectionality, barriers to health care, how social and cultural background can affect understanding of diagnosis and management. Interestingly, the skill "critically reflect on own values and beliefs" was the most important skill that the experts highlighted with $93 \%$ consensus.

Though critical reflection on own beliefs has been accepted as an essential skill by many of the existing guides or studies of cultural competence (Hordijk et al., 2018; NASW, 2015; Douglas, et al., 2014; Alizadeh \& 
Chavan, 2016; AAMC, 2012; SickKids, 2011), it does not seem that it has been well integrated in the teaching of cultural competence. More specifically, Lanting et al. (2019) analysed 968 questionnaires by medical teachers in Europe who self-reported their preparedness and training needs to teach cultural competence. With regard to critical reflection on own beliefs, the study showed that $74 \%$ of the respondents thought that care providers looked at health problems on the basis of their culture. With regard to themselves, $68 \%$ of the respondents answered that they see the health care systems on the basis of their culture, while $46 \%$ them were not sure if they could recognise whether their reactions were affected by stereotypes and they did not appear prepared to teach about prejudice and discrimination in health care. Seventy three percent (73\%) of the respondents were interested in being trained in how to teach about prejudice and discrimination in health care. The result of this study indicates that reflecting on own beliefs is an important skill for cultural competence and that this skill needs to be better integrated in the curricula.

Echoing the significance of cultural critical reflection and the gap identified by Lanting et al. (2019), Worden and Tiouririne (2018) described how their students did not like the integration of cultural competence in their program because students took discussion of culture-specific vignettes too personally, having difficulties in stepping back and approaching the described case critically. Therefore, it seems here that critical reflection on own beliefs is fundamental for the provision of health care, yet training in how to achieve this in medical education is lacking.

The usefulness of critical reflection on own beliefs and the need for training of medical students was apparent in our University as well, in accordance with the initial conclusion of the clinical communication skills tutors. Below we present the method we used in order to analyse the narratives of these tutors.

\section{Method}

The study of narratives has been well documented and acknowledged as an effective way to understand people's experiences (Clandinin \& Caine, 2013). The method of this study is informed by Nygren and Blom's (2001) method of "short reflective narratives", which is an alternative method of the study 
of narratives, in order to understand how people have experienced events. Through this method, researchers do not only ask participants to narrate their experience but at the same time to reflect so that participants delve deeper into it. Nygren and Blom (2001, p.370) more specifically explained that "narratives produced by a homogenous group provide a more direct focus on the respondents' way of defining and understanding an event. This is achieved by asking respondents to write down the story and then make an initial interpretation of what they have written". By reflecting on their experience, respondents give meaning to what they encounter. Nygren and Blom's method consisted of three stages of analysis. First, the researcher reads the narratives naively in order to get an idea of how narrators experienced the event. Second, the researcher structures the narrative in a way to find interconnected meanings which would help to give interpretion more depth. Third, the naive understanding of the narrative in the first stage is merged together with the meanings from the second stage in order to come up with a meaningful interpretation. Nygren and Blom's method has been used by many other researchers (e.g. Papadaki \& Papadaki, 2008; Braye et al., 2011).

In order to achieve Nygren and Blom's three stages of analysis we naively read (first stage) the spontaneous expression of feelings by one clinical communication tutor (the tutor we started our Introduction with). The idea we gathered was that examining cultural competence in OSCEs is challenging and that students could not critically handle their own beliefs. From this initial idea we asked all tutors (three) who prepared and examined the cultural competence OSCE station to describe in a reflective manner their experience with preparing and examining the cultural competence OSCE station and their discussion with students. This provided us with an opportunity to get an idea of what happened and how the tutors understood the event.

To structure the tutors' reflective narratives (second stage), we relied heavily on Gibb's reflective cycle for development (Gibbs, 1988; Dye, 2011). More specifically, the tutors expressed their experiences on the basis of the following: description of the experience, feelings, evaluation, analysis, conclusion, and action plan. These headings worked as deductive themes for the analysis of tutors' stories. The tutors expressed their experience in writing but also through conversation with the first author of this paper. 
Considering the naive reading from stage one and the structure and themes from stage two, we proceeded with the interpretation, conception and construction of a model (stage three) for tackling in the future the challenges that the tutors experienced. We placed emphasis on stage three as it reflects Gibbs' last step "action plan" where all insights and experiences from previous steps are merged together to handle prior challenges and help learners develop. Stage three is also along the lines of Thomas' (2006) general inductive analysis. That is, coding, analysis and construction of a model.

The presentation of the results below is organized around the second stage and the deductive themes, namely description of the experience, feelings, evaluation, analysis, conclusion, and action plan.

\section{Findings}

\section{Description of the Experience}

The objective of this section of reflection is for the participants to describe the experience or the event. Any feelings or evaluation should be presented in the following sections. The description of the experience would help the narrator better reflect by evaluating, analysing and thinking of any action plans.

All three tutors narrated their experience and the context in a similar way. More specifically, they explained that at the University of Nicosia a Cultural Competence Training Team (CCTT) integrated cultural competence in the curriculum of the MD6 medical program from Year 1 to Year 6. The framework for building and integrating cultural competence took the form of a spiral stepladder where the first step (Year 1) was about acquiring knowledge about the social and cultural determinants of health; the second step (Years 1 and 2) focused on applying knowledge to cases and acquiring some basic skills in cultural communication; the third step (Year 3 to 6) helped students to master skills in a simulated environment so to provide cultural competence care [the stepladder model of cultural competence at the University of Nicosia has been published (Constantinou et.al., 2020)].

The tutors carried on explaining that part of the integration process was the examination of cultural competence in OSCEs (Objective Structured 
Clinical Examinations). As a result, an OSCE station was prepared by three clinical communication tutors and aimed to assess cultural competence. The scenario involved a Muslim patient with diabetes who wanted to fast during the upcoming Ramadan and did not know how to do it without compromising her diabetes control. A member of the CCTT had reviewed the relevant literature and drafted a scenario drawing from relevant literature. The literature highlighted the importance of this issue among Muslim patients with diabetes, the health implications and the health guidelines published online to help patients with diabetes fast during Ramadan without adverse effects on their health. Although in Islam patients are excused from such a religious practice, there are patients who still want to fast. The station was critically revised by two more tutors and was further reviewed by the Assessment Lead and the Clinical Communication Lead before it was finalised and used in the exam.

The tutors advised that the station ran smoothly and that all students passed this particular station. However, during the OSCE debriefing after the exam a small number of Muslim students commented that the station was not realistic as it did not capture the Islamic practice of fasting, that Muslim patients do not need to fast and that the station had put students in a disadvantage, compared to their peers, as Muslim students had to be examined in a problematic OSCE setting. The tutors advised that during the debriefing they tried to explain to the students that the station reflected some basic literature and that there were Muslims who indeed wanted to fast even though they were exempt by their religion. Attempts to assuage students were not successful; the students were resolute in their critique of the OSCE.

\section{Feelings}

The tutors expressed a mixture of feelings because the event itself did not meet most of their expectations. To elaborate, because all students had passed the exam, student criticism caught the tutors by surprise. In addition, the tutors expressed ambivalence. They were confused and disappointed and at the same time worried that they had done something wrong with the preparation of the OSCE station. They engaged in a process of questioning their academic actions. More specifically, a tutor said that what crossed his 
mind was that he did something really wrong and that he might have not read the literature appropriately, underestimating student's understanding:

Maybe I rushed it, I misread the literature and I wrote the station in contrast to what really happens.

Another tutor advised:

I thought that this was a well written station; maybe the students had not prepared well and they just wanted to justify their performance.

However, at the same time there was ambivalence. The same tutor said:

Maybe, students had a point, we need to look deeper into it and revisit the station".

Interestingly, apart from questioning themselves they also questioned student intentions. They thought that the criticism was generated by some Muslim students who either took the station personally or thought that the scenario and the simulated patient were intended to represent Islam. In addition, they felt that the students had not prepared well and this was why they found the station challenging.

\section{Evaluation}

In this section the tutors tried to consider what went well and what did not work as expected, without analysing. The tutors will analyse by exploring the reasons why things did not go as expected in the following section.

The tutors largely focused on the academic aspects of the station in order to support their thoughts about what worked well. For example, a tutor said

The station was well written. That worked well. It was prepared on the basis of literature about Muslims and fasting, it reflected taught material, and it examined the basic cultural competence skills which are found in the guidelines. What also worked well was the fact that all students passed the station. 
With regard to what did not work that well tutors focused on student perceptions rather than on the quality of the station. That is, as one tutor explained:

Students did not like the station because they did not see the relevance and the importance. If they had studied the material more carefully they would have appreciated the station more.

In addition, another tutor said:

Students tend to see problems; they think they are always right.

\section{Analysis}

Here the tutors analysed the event by expanding on the previous section of evaluation. They considered why things went well, why did not go well, what they understood from the event and how their prior background and knowledge could help them make sense of their experience.

Because tutors considered the station as well written based on existing literature, they understood that it effectively examined listening skills, empathy (showing understanding of the patient's perspective), being nonjudgmental, involving the patient in shared decision making. The tutors backed up their thoughts by explaining that the fact that all students passed the station confirmed that students were taught well and the station was well prepared.

Interestingly, the tutors advised why some things did not work as expected. More specifically, the tutors acknowledged that the station did not meet the expectations of some students, especially the Muslim ones who had difficulties to accept that the simulated patient was telling something that they did not expect to hear (i.e. to fast while being sick). At this stage, tutors started realising that it was not the station itself that had a problem but the fact that students were not taught how to handle their expectations and critically reflect on their own cultural beliefs. A tutor said:

Considering the situation more carefully I think that student feedback helped us understand that we had omitted something and 
this did not have to do with the station. Looking again at some basic skills for cultural competence it seems that a critical skill is that of critical reflection on own beliefs. We never taught students how to do it and we expected Muslim students to critically approach their own beliefs and effectively handle a patient who was telling something they did not believe was right. That definitely required more emotional and cognitive labour.

Another tutor drew from the conversation with the students to support the same analysis and said:

After a long discussion with the students they acknowledged that the main problem was that they could not distance themselves from their own cultural and religious background and, as a result, they could not accept that what their patient was saying was reasonable.

\section{Conclusion}

As Nygredn and Blom explained, a homogenous group can provide a more coherent story of what happened. As the three tutors had similar background and training and all participated in the preparation of the OSCE station, they all reached the same conclusion. Under Gibbs' reflective cycle, conclusion relates to anything else learners could have done. The tutors reached the conclusion that they could have not prepared the station differently but they could have better prepared the students to work with the station more effectively. On this note, the tutors made it very clear that this should not happen again and that, as a result, they suggested a specific pathway which is further discussed under the next step in Gibbs's cycle.

\section{Action Plan}

According to Gibbs' guidelines, an action plan refers to what people could do if they experienced the same situation. An action plan is a fundamental step in Gibbs' reflective cycle because it brings all the previous stages together and works as evidence that learners have developed in a positive way. The action plan that the three tutors suggested resulted reasonably from their experience and was consistent. That is, students have to be trained in 
how to critically reflect on their own beliefs as per the guidelines on achieving cultural competence. A tutor explained

I know that critical reflection on own beliefs is an important skill that is found in many guidelines on cultural competence. However, I am not aware of any specific guidelines or teaching plans in terms of how to do this. Maybe we need to come up with a teaching plan. This teaching plan has to be informed by the literature.

Drawing from the tutors' experience, evaluation, analysis, conclusion and suggested action plan and the fact that the literature shows a gap in ways to train medical students and doctors in how to critically reflect on their own beliefs, below we present a model of achieving critical reflection on own beliefs which is theoretically informed. Because the gap in training students in how to critically reflect on their own cultural beliefs is big and because Gibbs' last step of action plan is fundamental for learners' development, we decided to delve deep into the literature and construct a training model thoroughly. Let us start with the theoretical foundations of our model.

\section{Theoretical Foundations of the Model}

Having concluded that the main problem was students' difficulty to distance themselves from their beliefs and the absence of relevant training, we first turned to the available literature in the critical thinking models.

A highly influential approach which could inform reflection on own beliefs was developed by Mezirow (1990). Mezirow explained that people rely on their prior learning in order to assess whether their actions were appropriate in a particular situation. However, people need to become aware of their own presumptions to critically evaluate their decisions and subsequent actions. This would result in challenging their pre-existing and well-established template of knowledge in, and understanding of, their world; such an act of challenging would mean questioning the sense of self. Mezirow explained that critical reflection is important for transforming people's learning because it involves re-evaluation of their thinking and actions. 
Such a context of self-knowledge and evaluation has been found in other models as well. Purnell (2018, p. 98-101) presented a few models of critical thinking which could be used for reflecting on own culture. More specifically, Purnell presented Carper's "ways of knowing"; one important way of knowing is personal knowledge, which is achieved when people acquire knowledge about themselves and they place themselves in contexts for being challenged by others and ultimately self-reflect on their own practice. This process could help people go deeper into their personal beliefs and understand how and why they make assumptions. Another way of knowing is empirical knowledge, which derives from research and the sciences. Therefore, people should approach themselves through evidencebased information.

In addition to ways of knowing, Dewey's model of reflection has been very prominent and has four criteria (Purnell, 2018). First is a process of deeper understanding of one's self. Second, reflection should be systematic and scientifically based. Third, reflection happens within the self and in relation to other people. This is because social interaction may change people's worldview. Fourth, reflection should depend on attitudes that appreciate diversity. Ryan (2005) simplified Dewey's approach and placed emphasis on being critical towards established truths, unpacking the assumptions behind claims and the interests behind people's claims.

An alternative model of critical reflection is the one outlined by Habermas and highlights three types of knowledge (Purnell, 2018). Work knowledge refers to the knowledge derived from scientific inquiry. Practical knowledge results from social interaction, such as social norms and values. Emancipatory knowledge refers to knowledge of the self and self-reflection. In other words, knowledge is acquired through self-reflection which results in transforming one's consciousness.

There are other models which add more dimensions to what is presented above. More specifically, Kolb's (2001) model of experiential learning is very popular for developing one's skills. Kolb explained that one could describe their experience, think about what went well and what could have been done differently, approach it on the basis of other knowledge and make a plan for change. Another concept which can be used as a template for critical evaluation of own beliefs is the concept of "sociological imagination" coined by C. Wright Mills (cited in Giddens, 2017). Sociological imagination 
is very popular in Sociology and it is taught early on in introductory courses or lectures. The term refers to a mental exercise to approach familiar phenomena as new in order to understand them more holistically by approaching and understanding phenomena as part of broader social, cultural, economic and political processes.

All of the models and the concepts above share a common basis. That is, people can transform their way of thinking by developing new knowledge and attitudes from systematic and scientifically-informed critical reflection of their own practice. The question is how can this be achieved? To answer this question, a basic challenge needs to be dealt with and this derives from people's difficulty to make correct judgements. When people make judgments, they make "person attributions" and "situation attributions" (Walinga \& Stangor, 2014). When they judge themselves they make person attributes for positive outcomes and situation attributes (blaming the context) for negative outcomes. In other words, people tend to blame the situations and not themselves if the outcome is unfavourable. This is called the "fundamental attribution error" and it occurs because people cannot see their self from a distance and critically reflect on their behavior (Walinga \& Stangor, 2014; Ross, 1977; Kelley, 1967). So the challenge here is to help people see themselves in the social environment in which they act. This can be done using a number of techniques, such as introspection, peer observation and discussion or video recording one's own performance and self-reflection. Below we propose a model or course of learning in how to achieve critical reflection on own beliefs, resulting in building upon one's cultural competence.

\section{The SCCIL model}

Considering the models and concepts presented above and tutors' experience with examining cultural competence in OSCEs, we are proposing a training model for medical students (figure 1), organized into two pathways, the theoretical and the practical. The theoretical pathway is an amalgamation of the models and concepts presented above and it informs the construction of the practical pathway. 


\section{Theoretical pathway}

According to the theoretical pathway (see top part of figure 1) learning how to critically reflect on own beliefs requires the following: understanding the self by observing it on the basis of new knowledge and insights about the self, critically approaching the self (reflection, sociological imagination, evaluation) and actualisation (taking appropriate actions). In other words, it is about understanding, reflection and action. These theoretical steps inform the practical pathway (bottom part of figure 1), which is described in detail below.

\section{Practical pathway}

The practical pathway is the backbone of our model and involves specific activities. These activities can take place as a series of steps. That is, one preparatory brainstorming step and four hands-on steps. The hands-on steps are the main pillar of the model because they are building up the skill of critical reflection. These are: See or visualise own beliefs, Critical understanding of own beliefs, Critical evaluation of clinical practice, and illustration; hence the abbreviation SCCIL. Each step is elaborated below.

Preparatory step: Thinking of own beliefs. Because imagining one's own beliefs outside the self is a demanding task as pointed out by Walinga and Stangor (2014) and it might be cause for revisiting one's sense of self (Mezirow, 1990), students could first start thinking of the possible assumptions they make and the stereotypes they activate in order to start understanding themselves. This can be achieved by brainstorming questions which can help students think what stereotypes are, examples of stereotypes and why people use stereotypes. Following a discussion, students could then learn more by confirming or refuting their pre-existing knowledge through having been presented with scientific knowledge from psychological and sociological literature on stereotypes. When students know that people in general make assumptions and activate stereotypes, they are likely to start thinking that they themselves might do the same. This step is for preparing students to build their skill in how to critically reflect on their own beliefs and values in the following steps. In other words, moving from thinking about their own beliefs to seeing or visualising their beliefs in the next step. 
Step 1: Seeing or visualising own beliefs. In order to enhance their understanding of themselves, students could participate in an exercise which would help them observe themselves; start seeing in practice that they have beliefs and make assumptions. Within the context of this exercise, students could be shown a picture and asked to say what they think about the person's character or job, hobbies and so forth. The idea is to place students in a state of making judgments on the basis of no information. At the end of the exercise students would discuss how they made these judgments and understood that they had just activated assumptions on the basis of physical appearance. The discussion would then carry on with regard to the possible consequences for the judged person but also for themselves and in relation to the likelihood of activating assumptions in all kinds of social encounters.

Step 2: Critical understanding of own beliefs. Having thought and visualised their own beliefs, during this step students could actively engage in a critical evaluation of themselves, putting into practice their selfreflection and sociological imagination. Students could think of a cultural belief they have or a tradition or custom they highly value and practise. They could then imagine that this is something alien to them and understand it holistically and within broader and social implications. Students could immerse themselves in this kind of introspection by asking and answering questions. For example, Why do people have this belief? Why do I have this belief? How does it help people? Where did it come from? What happens if people do not follow it? Has this belief changed over time? How does this belief help people construct relations? This is an exercise to help students activate their sociological imagination, which could prepare them for doing the same in challenging environments in health care settings.

Step 3: Critical evaluation of clinical practice. Having acquired knowledge in the basic principles and engaged in exercises to see and critically reflect on their own beliefs, students could then critically evaluate cases of clinical practice. They could work in small groups to think and evaluate short real scenarios of interactions between clinical practitioners and patients. The scenarios could be revealed to the students gradually so that students could think of the way forward before they find out how the stories unfolded. Students would discuss questions such as: How do you feel about this scenario? Could you think of any assumptions which might accrue? What might happen if these assumptions are brought to the fore? What do 
you think that doctor should do next? After discussing these questions, students could be presented with the healthcare professionals' actions and invited to discuss the following: How would you evaluate the doctors' approach to the patient? What do you think guided the doctor's behaviour? How should the doctor approach the patient differently?

Step 4: Illustration of or showing own skill of critical reflection on own beliefs in a simulated or workplace-based environment. The final step is about putting everything together and doing critical reflection on own beliefs and values. The word illustration here is important because it refers to students' ability to illustrate or show in a simulated environment their skills acquired from the previous steps. In order to achieve this, a simulated patient could work with students on a specific scenario. The simulated patient could place emphasis on a cultural belief of theirs and challenge a specific students' belief. For example, the simulated patient could challenge students' beliefs in the effectiveness of contemporary biomedicine. Students could be given a task and asked to communicate with the simulated patient effectively. This hands-on exercise will give students the opportunity to be mindful of their assumptions, recognise that any emotions accruing stem from their personal belief and deal with their emotions without letting them mediate between their communication with their patients. Students could then explore their patient's perspective in depth and understand that their patients' belief is important for them. Having understood the importance of being critical towards their own beliefs, students should see their own belief critically and explore their patient's criticism in a non-judgemental way. 


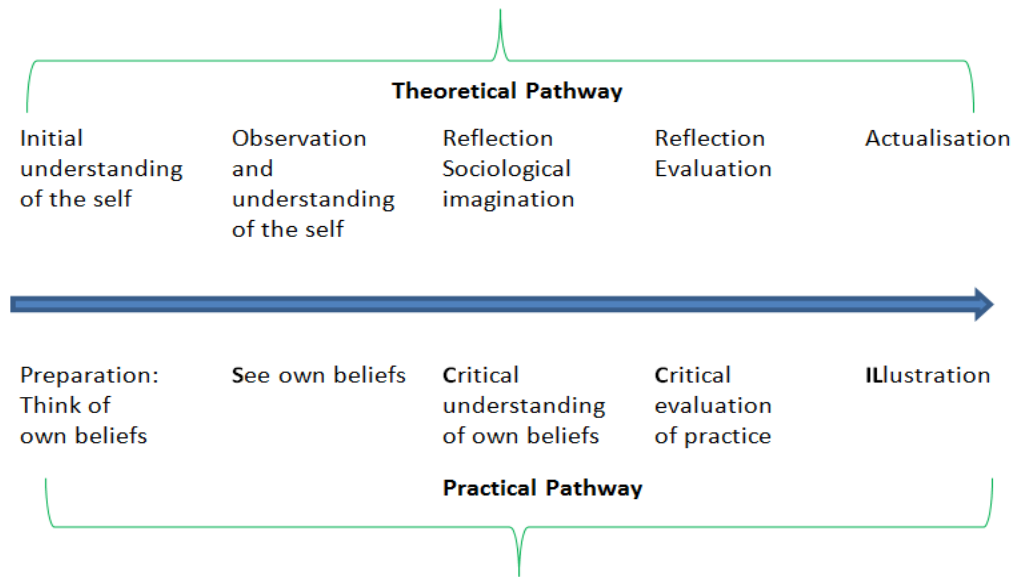

Figure 1. The SCCIL model for achieving critical reflection on own beliefs and values within the context of cultural competence in medical education

\section{Discussion}

In this article we explored and analysed short reflective narratives from three clinical communication tutors who had prepared a cultural competence OSCE station and assessed medical students. During a debrief session, students were very critical of the specific station. One tutor spontaneously expressed feelings, which triggered us to explore in more depth the experiences from all three tutors by using Nygren and Blom's (2001) method of analysing short reflective narratives. The narratives were structured on the basis of Gibbs' reflective cycle and helped us better unpack tutors' understanding of what happened and what should happen in the future. The tutors' main conclusion was that students could not distance themselves or critically handle their own cultural beliefs and that they should be trained in how to achieve this.

The literature reflects the tutors' short narratives and conclusion. More specifically, studies and models of cultural competence have shown the importance of critical reflection on own beliefs in order to ensure good quality and non-judgemental provision of healthcare (Lanting et al., 2019; 
Hordijk et al., 2018; Douglas et al., 2014). However, teaching critical reflection on own beliefs in medical education has been a challenging endeavour. In order to fill in this gap and act upon the three tutors' action plan, we drew together the experiences of three clinical communication tutors based on their reflective narratives, the literature, and the basic models of critical thinking in order to propose a conceptual model of training medical students on how to critically reflect their own beliefs. The model is abbreviated as "SCCIL", from the practical steps seeing own beliefs, Critical reflection on own beliefs, Critical reflection on practice and illustration. The abbreviation SCCIL resembles phonetically the word "skill" to place emphasis on the need to develop the skill of reflection on own beliefs.

The SCCIL model has various advantages. First, it has been inspired by an unexpected experience arising from the assessment of cultural competence at the University of Nicosia. Second, it is theoretically informed and based on preexisting models of critical reflection (Purnell, 2018). In addition, it deals with the challenges raised by Mezirow (1990) and Walinga and Stangor (2014) with regard to people's difficulty to challenge and see themselves from a distance. Third, it is a model that follows a logical building-up procedure starting from more abstract experiences and moving towards more specific and hands-on practice. Fourth, it is not very prescriptive, allowing flexibility to accommodate the teaching needs of medical programs. Fifth, it could be used to train students in other skills, such as communication and clinical skills.

The first two advantages reflect what others have done while constructing models (Alizadeth \& Chavan, 2016) and how others have on their own experience (i.e. Worden \& Tiouririne, 2018). The remaining advantages fill in an identified gap by providing a practical pathway to train students on how to critically reflect on their own beliefs, an identified need in medical education (Lanting et al., 2019; Sorensen et al., 2019; Hordijk et al., 2018; Douglas et al., 2014).

The SCCIL model has some limitations. The various steps described remain to be measured and tested both at process and at outcome level. In addition, it requires facilitators with good understanding of social theory and social sciences. Teachers from other academic backgrounds could teach critical reflection on own beliefs but they have to be well trained. This might place pressure on University resources. Finally, the model might not fit well 
with programs that do not have small groups teaching or do not have a budget to recruit simulated patients. Despite these limitations, we believe that the SCCIL model can be easily implemented and initially tested through student feedback. It can be better measured with one of the cultural competence tools or through situational judgement test (George, 2017). The model can be the basis for training clinicians and exploring its impact, within the context of cultural competence, on health outcomes.

\section{Conclusion}

The skill of critically reflecting on one's own beliefs has been considered by a number of scholars as important for building up cultural competence and it was the main reason why medical students were critical of a cultural competence OSCE station that three clinical communication tutors had prepared. This paper analysed the narratives of these three tutors who concluded that a training session should be designed in order to better prepare medical students to critically reflect on their won beliefs. As a result of the analysis and acting upon the conclusion of the tutors, we propose the SCCIL model for training medical students in the process of critical reflection of their own beliefs in a simulated environment. The model, which is theoretically informed, could also be used for training doctors and investigating its impact on patient satisfaction, adherence to therapy and other health outcomes.

\section{Notes}

${ }^{1}$ OSCE stands for Objective Structured Clinical Examination and it involves hands-on performance by students who are observed and examined by a present examiner in a simulated environment. OSCEs are widely used in medical education and usually a simulated patient participates and acts on the basis of a scenario. Students have a specific task to do and they are examined on specific skills that they were taught before in small-group sessions.

\section{References}

Alizadeh, S., \& Chavan, M. (2016). Cultural competence dimensions and outcomes: a systematic review of the literature. Health \& Social Care in the Community, 24(6). https://doi.org.10.1111/hsc.12293 
Betancourt, J., Green, A. R., Carrillo, J. E., \& Ananeh-Firempong, O. (2003). Defining cultural competence: a practical framework for addressing racial / ethnic disparities in health and health care. Public Health Report, 118, 293-302. https://doi.org.10.1016/S00333549(04)50253-4

Borrell-Carrió, F., Suchman, A. L., \& Epstein, R. M. (2004). The biopsychosocial model 25 years later: principles, practice, and scientific inquiry. The Annals of Family Medicine, 2(6), 576-582. https://doi.org.10.1370/afm.245

Braye, S., Preston-Shoot, M., \& Wigley, V., (2011). Deciding to use the law in social work practice. Journal of Social Work, 13(1), 75-95. https://doi.org.10.1177/1468017311431476

Carballeira, N. (1997). The Live \& Learn Model for culturally competent family services. Continuum (Society for Social Work Administrators in Health Care), 17(1), 7.

https://pubmed.ncbi.nlm.nih.gov/10165619/

Clandinin, D. J., \& Caine, V. (2013). Narrative inquiry. In A. A. Trainor \& Graue E. (Eds.), Reviewing qualitative research in the social sciences (pp. 178-191). Taylor \& Francis.

Constantinou, C.S., Papageorgiou, A., Andreou, P. \& McCrorie, P. (2020). How to integrate cultural competence in medical curricula: learning from a new medical programme. MedEdPublish, 9(1), 11. https://doi.org/10.15694/mep.2020.000011.1

Constantinou, C. S., Papageorgiou, A., Samoutis, G., \& McCrorie, P. (2018). Acquire, apply, and activate knowledge: A pyramid model for teaching and integrating cultural competence in medical curricula. Patient Education and Counselling, 101(6), 1147-1151.

https://doi.org.10.1016/j.pec.2017.12.016

Cultural Competence (2011). Train-the-Trainer Manual. SicKids.

https://www.sickkids.ca/culturalcompetence/37976-NISN\%20\%20Train-the-Trainer\%20Manual\%20-\%202011.pdf

Douglas, M. K., Rosenkoetter, M., Pacquiao, D. F., Callister, L. C., HattarPollara, M., Lauderdale, J., Milstead, J., Nardi, D., \& Purnell, L. (2014). Guidelines for implementing culturally competent nursing care. Journal of Transcultural Nursing, 25(2), 109-121. https://doi.org/10.1177/1043659614520998 
Dye, V. (2011). Reflection, reflection, reflection. I'm thinking all the time, why do I need a theory or model of reflection?'. In D. McGregor \& L. Cartwright (Eds.) Developing Reflective Practice: A guide for beginning teachers (pp. 217-234). McGraw-Hill Education.

Expert Panel on Cultural Competence Education for Students in Medicine and Public Health (2012). Cultural competence education for students in medicine and public health: report of an expert panel. Association of American Medical Colleges and Association of Schools of Public Health. https://www.pcpcc.org/resource/culturalcompetence-education-students-medicine-and-public-health

George, R. E. (2017). How to Better Teach and Evaluate Diversity Education in the National Health Service and Health Educational Institutions in the United Kingdom (Doctoral dissertation). University of Leicester.

Gibbs, G (1988) Learning by doing. A guide to teaching and learning methods. Further Education Unit at Oxford Polytechnic.

Giddens, A. (2017). Sociology ( $8^{\text {th }}$ ed.). Polity Press.

Hordijk, R., Hendrickx, K., Lanting, K., MacFarlane, A., Muntinga, M., \& Suurmond, J. (2019). Defining a framework for medical teachers' competencies to teach ethnic and cultural diversity: results of a European Delphi study. Medical Teacher, 41(1), 68-74. https://doi.org.10.1080/0142159X.2018.1439160

Horvat, L., Horey, D., Romios, P., \& Kis-Rigo, J. (2014). Cultural competence education for health professionals. Cochrane Database of Systematic Reviews, 5, CD009405. https://doi.org.10.1002/14651858.CD009405.pub2

Hudelson, P., Dogra, N., Hendrickx, K., Verdonk, P., Essink-Bot, M. L., \& Suurmond J. (2016). The challenges of integrating cultural competence into undergraduate medical curricula across Europe: experience from the $\mathrm{C} 2 \mathrm{ME}$ "Culturally competent in medical education" project. MedEdPublish, 5. https://doi.org.10.15694/mep.2016.000010

Kachur, E. K., \& Altshuler, L. (2004). Cultural competence is everyone's responsibility!. Medical Teacher, 26(2), 101-5. https://doi.org.10.1080/0141590410001667427 
Kelley, H. H. (1967). Attribution theory in social psychology. In D. Levine (Ed.) Nebraska Symposium on Motivation (pp. 192-238). University of Nebraska Press.

Kolb, D. A., Boyatzis, R. E., \& Mainemelis, C. (2001). Experiential learning theory: Previous research and new directions. In L. Zhang (Ed.), Perspectives on thinking, learning, and cognitive styles (pp. 227-247). Lawrence Erlbaum Associates.

Lanting, K., Dogra, N., Hendrickx, K., Nathan, Y., Sim, J., \& Suurmond, J. (2019). Culturally competent in medical education-european medical teachers' self-reported preparedness and training needs to teach cultural competence topics and to teach a diverse class.

MedEdPublish, 8. https://doi.org.10.15694/mep.2019.000098.1

Leininger, M. (2002). Culture care theory: A major contribution to advance transcultural nursing knowledge and practices. Journal of

Transcultural Nursing, 13(3), 189-92. https://doi.org.10.1177/10459602013003005

Mezirow, J. (1990). Fostering critical reflection in adulthood. Jossey-Bass Publishers.

National Association of Social Workers (2015). Standards and indicators for cultural competence in social work practice. NSAW. https://nlasw.ca/sites/default/files/inlinefiles/cultural_competency_standards.pdf

Nygren, L., \& Blom, B. (2001). Analysis of short reflective narratives: a method for the study of knowledge in social workers' actions.

Qualitative Research, 1(3), 369-384. https://doi.org/10.1177/146879410100100306

Papadaki, E., \& Papadaki, V. (2008). Ethically difficult situations related to organizational conditions: Social workers' experiences in Crete, Greece. Journal of Social Work, 8(2), 163-180. http://citeseerx.ist.psu.edu/viewdoc/download?doi=10.1.1.893.920\&r ep=rep $1 \&$ type $=$ pdf

Price, E. G., Beach, M. C., Gary, T. L., Robinson, K. A., Gozu, A., Palacio, A., Smarth, C., Jenckes, M., Feuerstein, C., Bass, E. B., \& Powe, N. R. (2005). A systematic review of the methodological rigor of studies evaluating cultural competence training of health professionals. 
Academic Medicine, 80(6), 578-586.

https://doi.org.10.1097/00001888-200506000-00013

Purnell, L. (2002). The Purnell model for cultural competence. Journal of Transcultural Nursing, 13(3), 193-6.

https://doi.org.10.1177/10459602013003006

Purnell, L. (2018). Critical reflection. In D. Pacquiao \& L. Purnell (Eds.), Global applications of culturally competent health care: guidelines for practice (pp. 98-101). Springer International Publishing.

Renzaho, A. M. N., Romios, P., Crock, C., \& Sønderlund, A. L. (2013). The effectiveness of cultural competence programs in ethnic minority patient-centered health care - a systematic review of the literature. International Journal for Quality in Health Care, 25(3), 261-269. https://doi.org.10.1093/intqhc/mzt006

Ross, L. (1977). The intuitive psychologist and his shortcomings:

Distortions in the attribution process. Advances in Experimental Social Psychology, 10, 173-220. https://doi.org/10.1016/S00652601(08)60357-3

Ryan, J. (2005). Working toward inclusive leadership. Paper presented at the annual meeting of the American Educational Research Association, Montreal, Canada.

Sorensen, J., Norredam, M., Suurmond, J., Carter-Pokras, O., GarciaRamirez, M., \& Krasnik, A. (2019). Need for ensuring cultural competence in medical programmes of European universities. BMC Medical Education, 19(1), 21. https://doi.org.10.1186/s12909-0181449-y

Sorensen, J., Norredam, M., Dogra, N., Essink-Bot, M. L., Suurmond, J., \& Krasnik, A. (2017). Enhancing cultural competence in medical education. International Journal of Medical Education, 8, 28-30. https://doi.org.105116/ijme.587a.0333

Thomas, D. R. (2006). A general inductive approach for analyzing qualitative evaluation data. American Journal of Evaluation, 27(2), 237-246. https://doi.org/10.1177/1098214005283748

Walinga, J., \& Stangor, C. (2014). Introduction to Psychology $\left(1^{\text {st }}\right.$ Canadian Ed.). BCcampus. 
Waxler-Morrison, N., Anderson, J. M., Richardson, E., \& Chambers, N. A. (2007). Cross-cultural caring: a handbook for health professionals ( $2^{\text {nd }}$ ed.). UBC Press.

Worden, M. K. \& Tiouririne, N. A. D. (2018). Cultural competence and curricular design: learning the hard way. Perspectives on Medical Education, 7(1), 8-11. https://doi.org.10.1007/s40037-018-0428-7

Costas S. Constantinou is an Associate Professor of Medical Sociology and Associate Dean for Students at the University of Nicosia Medical School, Cyprus.

Panayiota Andreou is an Assistant Professor of Clinical Communication at the University of Nicosia Medical School, Cyprus.

Alexia Papageorgiou is a Professor of Clinical Communication and Chair of the Centre of Medical Education at the University of Nicosia Medical School, Cyprus.

Peter McCrorie is a Professor of Medical Education and Chair of the International Advisory Committee for the Health Sciences at the University of Nicosia Medical School, Cyprus. He is Emeritus Professor at St George's, University of London.

Contact Address: Costas S. Constantinou, Office 110, 1st floor, University of Nicosia Medical School, 21 Ilia Papakyriakou, 2414 Engomi POBox 24005, CY-1700, Nicosia, Cyprus. Email: constantinou.c@unic.ac.cy 